\title{
A ENFERMAGEM E A TECNOLOGIA APROPRIADA - ADEQUAÇÃO DA PRÁTICA Ȧ REALIDADE BRASILEIRA
}

\author{
Nalva Pereira Caldas *
}

ReBEn/08

CALDAS, N.P. - A Enfermagem e a Tecnologia Apropriada - Adequação da Prática à Realidade Brasileira. Rev. Bras. Enf.; DF, $35: 81-94,1982$.

\section{INTRODUÇĀO}

\begin{abstract}
"Aquele que tenta perscrutar com humildade e perseverança os segredos da natureza, ainda que disto não tome consciência, é como que conduzido pela mão de Deus, que sustenta todas as coisas, fazendo que elas sejam o que são."
\end{abstract}

\section{Albino Aresi}

O Tema III do XXXIII Congresso Brasileiro de Enfermagem a realizar-se em agosto próximo em Manaus tem o propósito de abordar "A Enfermagem e a Tecnologia Apropriada - Adequação da Prática à Realidade Brasileira".

A Associação Brasileira de Enfermagem, promotora do referido congresso, visa, com o estudo, a alcançar os seguintes objetivos:
- Analisar a evolução da tecnologia de enfermagem frente à evoluçāo da ciência e da tecnologia.

- Discutir sobre a realidade da tecnologia na assistência de enfermagem no Brasil.

- Discutir as implicações da evolução da tecnologia no ensino, assistência e pesquisa de enfermagem.

- Debater sobre os fatores favoráveis e desfavoráveis a adequação da prática à realidade brasileira.

- Debater sobre as tendências da prá'tica da enfermagem face à evolução da tecnologia apropriada.

Sabiamente, a Diretoria da ABEn Seção do Espírito Santo, incluiu na programação comemorativa da XLII Semana de Enfermagem, a mesma matéria, conduzindo, assim, as enfermeiras à sua reflexão prévia sobre o assunto, o que certamente resultará em estímulo

* Professora Adjunta de Administração de Enfermagem da Faculdade de Enfermagem da Universidade do Estado do Rio de Janeiro; Livre Docente pela Pontifícia Universidade Católica do Rio de Janeiro. 
CALDAS, N.P. - A Enfermagem e a Tecnologia Apropriada - Adequação da Prática à Realidade Brasileira. Rev. Bras. Enf.; DF, 35 : 81-94, 1982

à participação nesse grande conclave anual.

O assunto é palpitante e pertinente, pois aqui e ali se nota certo ressentimento dos enfermeiros mais antigos por uma aparente alienação dos mais jovens quanto aos aspectos tecnológicos da profissão.

O pensamento de KANT é de que "A teoria sem a prática é vazia e a prática sem a teoria é cega".

$\mathrm{Na}$ realidade, na vigência da Lei $n .^{\circ}$ 775/49 que regia o ensino da enfermagem, as escolas brasileiras enfatizavam muito a prática das ações de enfermagem. Depois do ingresso das escolas nas universidades, nota-se maior ênfase no referencial teórico. Como toda virtude está no equilíbrio, espera-se que a partir das discussões em torno do tema encontrem os enfermeiros a medida certa em que os conteúdos teórico-práticos devam ser utilizados.

No presente trabalko, pretende-se analisar os diversos fatores que contribuíram até o momento para a evolução da tecnologia da enfermagem brasileira.

Não foi possivel aprofundar o estudo a ponto de apresentar conclusões sobre a adequação da prática à realidade brasileira, pois isto demandaria acurada pesquisa.

A análise agora feita poderá contribuir para aqueles que estiverem interessados em prosseguir o estudo, pois muito há a ser explorado. Por exemplo: um inventário da literatura existente em nosso meio sobre as técnicas e procedimentos, quais as linhas doutrinárias identificáveis nas obras existentes. A utilização deste referencial teórico; o nível de compatibilidade entre as prescrições teóricas e a prática profissional; os fatores que interferem na compatibilização ou não. Muitos outros questionamentos poderão ser levantados para que se tenha resposta fiel sobre a adequação às necessidades do País.
O assunto interessa de perto a autora do trabalho, na qualidade de professora de Administração de Enfermagem e estaria ligado ao seu programa de ensino, quando apresenta a unidade de Organização $\Theta$ Métodos (O \& M), especialmente o estudo de Manuais e unidade introdutória com que o aluno se defronta com os principios de administração. Não fora isto, a sua participação na elaboração de manuais de técnicas de enfermagem e de rotinas de exames justificaria o interesse pelo assunto.

\section{CONCEITUAC̣ÃO}

Considera-se como técnica a habilidade especial de executar ou fazer algo. A tecnologia tem um sentido mais amplo porque inclui os conhecimentos e princípios científicos aplicáveis a uma atividade humana ou ainda a ciência que trata das técnicas.

\section{OBJETIVOS}

GUIMARAES, no seu trabalho sobre "Tecnologia e Medicina", lembra que existe uma distinção fundamental antropológica entre as espécies animais e a capacidade de o homem desenvolver e usar ferramentas. Comenta ainda que com a tecnologia, desenvolveu-se "de acordo com os recursos e características culturais do ambiente gerador", lembrando que "...na era paleolítica, as ferramentas de trabalho $\mathrm{e}$ as armas eram de pedra lascada; na era neolítica, em conseqüência da evolução cultural do ser humano, passaram a ser de pedra poida".

Observa o autor que o desenvolvimento tecnológico sempre foi estimulado pelos valores humanos vigentes que, com a sua ampliação, se vão tornando cada vez mais complexos. Exemplifica, chamando a atenção como alguns povos 
CALDAS, N.P. - A Enfermagem e a Tecnologia Apropriada - Adequação da Prática à Realidade Brasileira. Rev. Bras. Enf.; DF, 35 : 81-94, 1982.

se caracterizaram por atividades científicas, tais como: a navegação e a luta armada. importante notar que o desenvolvimento científico sempre esteve ligado ao desenvolvimento cultural, embora nas primeiras eras tenha sido lento, acelerando-se após as grandes descobertas e inventos no século XIX e no sécculo XX, após a Segunda Guerra Mundial. Por outro lado, gera riquezas pelo aproveitamento dos recursos naturais e pelo emprego da força do trabalho.

TOFLER, em seu livro "Choque do Futuro", lembra que "A fim de atingir sem dificuldades um estágio superior de desenvolvimento econômico e tecnológico, toda sociedade precisa de um arsenal técnico de índices não só econômiccs como outros mais sensíveis e aptos a medir a realização dos objetivos sociais e zulturais."

Afirma ainda GUIMARĀES que o estímulo para o desenvolvimento da tecnologia médica, portanto da área de saúde, vem a ser "a necessidade de prolongar a vida e minorar o sofrimento".

\section{INFLUENCIAS SOBRE A TECNO- LOGIA DA ENFERMAGEM}

Muitos fatores contribuíram para a criação e o desenvolvimento da Tesnologia da Enfermagem Brasileira.

\section{1 - A Escola}

E comum afirmar-se que a época atual caracteriza-se pela velocidade das mudanças sociais. LOURENÇO FILHO julga altamente relevante o relacionamento entre a escola e a comunidade, considerando as várias interferências que as mudanças sociais ocasionam no sistema educacional. Reciprocamente, o processo pedagógiso é a forma social de pacificamente introduzir mudanças. $O$ mesmo autor julga que a escola que an- tes cumpria sua função de "manter a estrutura social estável" a'través da "...transmissão de técnicas, idéias, conhecimentos, ideais e aspirações..." deve no momento "...prever estágics que resultam de modificações tecnológicas e transformações conseqüentes na estrutura profissional de cada pais, sejam eles desenvolvidos, ou estejam em fase de desenvolvimento".

Compreendendo, assim, a grande influência que esta instituição social, a Escola, tem na evolução cultural de um povo, julga-se oportuno analisar a evolução educacional da área da enfermagem e a contribuição que os aparelhos formadores tiveram no desenvolvimento da tecnologia nacional.

A prática da enfermagem é tão antiga quanto o sofrimento humano.

Do descobrimento do Brasil até 1890 , a enfermagem era exercida de forma empírica, considerando-se que somente neste ano foi dado o passo inicial para a profissionalização dessa atividade humana. CARVALHO registra saída das irmās de caridade que atuavam no Hospício Pedro II, hospital destinado à assistência de doentes mentais, por motivos administrativos, quando resolveu a direção do nosocômio preparar pessoal para cobrir necessidades de mão-de-obra especializada para este objetivo específico, qual seja, o de assistir a pacientes psiquiátricos.

Além desta iniciativa, a mesma autora informa sobre o curso de pequena duração para voluntárias da Cruz Vermelha Brasileira desde 1914, destinado ao preparo de moças e senhoras "que desejassem servir ao País, tanto em 'tempo de guerra como em 'tempo de paz". Em 1916, a filial do Rio de Janeiro da Cruz Vermelha criou a Escola Prática de Enfermeira para o preparo de socorristas voluntárias para situações de emergência. Em 1920, a mesma organização teve a iniciativa de criar um curso 
CALDAS, N.P. - A Enfermagem e a Tecnologia Apropriada - Adequação da Prática à Realidade Brasileira. Rev. Bras. Enf.; DF, 35 : 81-94, 1982.

de visitadoras sanitárias, na pessoa de Amaury de Medeiros.

A reorganização da Saúde Pública em 1920, no Rio de Janeiro, e as constantes viagens de estudo de médicos brasileiros à Europa e aos Estados Unidos fizeram surgir nova mentalidade sobre o papel que a enfermeira poderia desempenhar nos programas gerais de saúde da populaçāo.

Os egressos dos primeiros cursos nāo satisfaziam às necessidades da comunidade naquele momento. Data desta éposa a inicia'tiva de José Plácido Barbosa da criação da Inspetoria de Profilaxia da Tuberculose quando sentiu a necessidade do enfermeiro como elo entre a família e o dispensário no sentido de orientá-las sobre problemas de contágio, higiene de modo geral $\Theta$ de Saúde Pública.

Dez anos após, 1966, havia 33 escolas, tendo diplomado 7.968 enfermeiros; em 1976, havia 42 cursos de graduação de Enfermagem e 14.810 diplomados.

Este ano, o Conselho Federal de Enfermagem informa haver 61 escolas estando inscritos 17.956 enfermeiros.

A necessidade de acelerar a melhoria do nível de assistência de enfermagem sarecia de soluções urgentes, a fim ce que a tecnologia adequada à prática pudesse contribuir para a diminuição dos índices de mortalidade do povo brasileiro. Em 1941, Lais Netto do Reys, vendo que havia seis escclas de enfermagem e que em vinte e tr'ês anos após a criação da primeira escola, havia apenas 1.300 enfermeiros, concluiu ser necessária a formação de pessoal em ou'tro nível. Assim, yor sua iniciativa, nasceu o primeiro curso para auxiliares de enfermagem que foi oficializado através da Lei n. ${ }^{\circ} 775$, de 1949.

Em 1956, o levantamento realizado pela ABEn revelcu existirem 43 cursos e 1.318 auxillares de enfermagem.
Em 1966, havia 75 cursos e 11.140 auxiliares de enferma,gem. Em 1976, existiam 97 cursos e 33.609 auxiliares de enfermagem. Atualmente, em 1980, o Conselho Federal de Enfermagem informa haver 202 cursos e 39.756 auxiiares de enfermagem.

O raciocínio utilizado para a criação do auxiliar de enfermagem, a necessidade de qualificar a assistência foi 0 mesmo para a criação do técnico de enfermagem. A discussão do assunto foi aberta em 1948, porém só foi concretizada com a criaçāo do curso em Pernambuco, em 1964, e no Rio, em 1965, pelos Conselhos Estaduais de Educação, após conclusão da ABEn.

O Relatório da Comissão de Documentação e Estudos da ABEn registra no ano de 1966 a instalação dos primeiros cursos no Rio de Janeiro: na Escola Ana Nery e Luiza de Marillac, em Gojânia na Escola São Vicen'te de Paulo e em Curitiba na Escola Catarina Labouré.

Em 1976, havia 63 cursos tendo formado 2.500 técnicos. Atualmentz, em 1981, o Conselho Federal de Enfermagem informa haver 219 cursos e 3.779 inscritos naquela Autarquia.

De 1890 a 1981 são passados 91 anos, quase um século de desenvolvimento da tecnologia da enfermagem a partir do processo educativo.

Apesar do crescimento do contingente humano para o serviço de enfermagem, sabe-se que vem sendo insuficiente para a demanda, considerando os quantitativos previstos pelo Plano Decenal de Saúde para as Américas e do propósito de "Saúde Para Todos no Ano 2.000". Há perspectivas animadoras considerando que antes do advento da Lei de Diretrizes e Bases havia vagas ociosas nas escolas e que agora no último vestibular unificado pela CESGRANRIO a proporçāo vaga-candidato foi de 1:12. Considera-se também a possibilidade de 
CALDAS, N.P. - A Enfermagem e a Tecnologia Apropriada - Adequação da Prática à Realidade Brasileira. Rev. Bras. Enf.; DF, 35 : 81-94, 1982.

ascensão do pescoal de nivel médio e atendentes aos quadros de auxiliares e técnicos de enformagem através dos exames de suplência profissionalizante. São medidas govərnamentais que forçam ou aceleram o desenvolvimento tecnológico.

\section{2 - Legislação do Ensino}

A necessidade de regulamentar o ensino para legitimar a utilização da tecnologia e mão-de-obra qualificada fez com que surgisse no Brasil a legislação adequada que responsabilizava o novo grupo e concedeu-lhe as prerrogativas necessárias ao exercício.

O primeiro documento legal sobre o ensino da enfermagem data de 1931 e trata da equiparação das escolas de enfermagem, normaliza a revalidação de diplomas e regula o exercício da enfermagem. O seu conteúdo chama a atenção "para o exercício dessa profissão, que vai exigindo nos povos mais adiantados um preparo técnico cada vez mais desenvolvido, outorgando-se mesmo às escolas que administram esse preparo as regalias de escolas superiores".

Em 1949, a Lei n. ${ }^{\circ} 775$, de 6 de agosto de 1948, disciplinou o funcionamento dos cursos de enfermagem e de auxiliar de enfermagem. Esta mesma Lei obrigava as instituições hospitalares a contratarem enfermeiras para a direção dos seus serviços. No mesmo ano, o Decreto n. ${ }^{\circ} 27.426$, de 14 de novembro, regulamentou a citada Lei, dando, assim, o currículo e disciplinou todo funcionamento dos cursos.

O currículo previsto assegurava o estudo das ciências da saúde, humanas e de tecnologia própria, geral e especializada nas várias áreas da enfermagem, além de recomendar práticas em instituições sanitárias e hospitalares.

Após o advento da Lei n. ${ }^{\circ} 4.024$, de 20/12/1961, que fixa as Diretrizes e Ba- ses da Educação Nacional, um novo fenômeno mudou o cenário da Educação da Enfermagem. As escolas que até então não estavam integradas em universidades tiveram que promover a sua reorganização. Em conseqüência, em 19 de outubro de 1962, o Conselho Federal de Educação aprovou o Parecer n. ${ }^{\circ} 271$ sobre o novo currículo mínimo do Curso de Enfermagem que veio a ser modificado através do Parecer n. ${ }^{\circ} 163$, de 28 de janeiro de 1972. A partir da Lei de Diretrizes e Bases, os Cursos de Obstetrizes foram unificados aos de Enfermagem, tendendo, assim, a uma única tecnologia.

Outro fenômeno interessante a registrar foi a criação da Licenciatura em Enfermagem, que possibilitou aos enfermeiros a formação do professor em nível de $2 .^{\circ}$ grau (Parecer $n .{ }^{\circ} 837$, de 6/12/68). Assim, os enfermeiros estarão aptos ao exercício do magistério em cursos de técnicos e de auxiliares de enfermagem.

Todo o sistema educacional de enfermagem está respaldado em dispositivos legais, porém, sabe-se que muitos estudos estão sendo desenvolvidos, principalmente no ensino superior, a fim de que sejam encontradas soluções mais consentâneas com as reais necessidades da comunidade, na formação do enfermeiro e no uso da tecnologia.

\section{3 - Influênsia da Literatura}

Nas décadas de quarenta e cinqüenta, as primeiras produções científicas surgiram como recurso documental e forma de cristalizar a tecnologia. A primeira obra publicada por Zaíra Cintra Vidal, uma das primeiras brasileiras a ser diretora da Escola de Enfermeiras Ana Nery, intitulou-se "Técnica de Enfermagem". A guisa de apresentação, assim ela se expressou: 
CALDAS, N.P. - A Enfermagem e a Tecnologia Apropriada - Adequação da Prática à Realidade Brasileira. Rev. Bras. Enf.; DF, 35 : 81-94, 1982.

\section{"RAZÃO QUE ME LEVOU A ESCREVER ESTE LIVRO}

\section{DUAS PALAVRAS}

Foi observando as dificuldades das alunas do curso de Enfermagem da nossa Escola que resolvi escrever este pequeno compêndio. E um livro inspirado no "Nursing Procedures" do Philadelphia General Hospital, p o r é m, com as devidas adaptaçōes à nossa técnica e ao nosso País.

Nele procurei descrever toda a técnica da enfermagem moderna, observando os seus principios e objetivos.

Foi escrito de acordo com o assunto dado pelo "Curriculum of School of Nursing”, programa este adotado na nossa Escola.

E o primeiro trabalho em português que aparece sobre esta cadeira e desejo que possa ser bem útil às nossas estudantes e à nossa profissão."

A obra que ela chamava de pequeno ccmpêndio possuía 420 páginas.

Além desta, a professora Zaíra Cintra Vidal publicou "Drogas e Soluçōes" e "Técnica de Ataduras".

Em 1951, Nancyli de Souza Virgolino de Alencar publicou o seu livro "Guia de Enfermagem em Saúde Pública”, também fruto de experiência nesta área, nos Estados Unidos e aqui na nossa pátria. Ao prefaciá-lo, Anna J. Nava chamou a atenção para a nossa dependência de livros estrangeiros em todos os ramos da Enfermagem.
Em 1977, Elvira de Felice Souza publicou o "Novo Manual de Técnica de Enfermagem", que já foi reeditado oito vezes e atualizado até o presente. No seu prefácio, Olga Salinas Lacorte declara ser o livro fruto da "solicitação constante de enfermeiras de todo o Brasil".

Os três primeiros livros brasileiros de enfermagem foram assim publicados no Rio de Janeiro, berço da profissão e o primeiro centro difusor e irradiador de tal mister ao qual se dedicava grande contingen'te feminino provindo de todas as regiōes brasileiras, especialmente do Nordeste.

O conteúdo destas obras citadas prendia-se a aspectos tecnclógicos da Enfermagem e chamava a atenção para princípios básicos de racionalização do trabalho: ordem, segurança, economia de tempo, esforço e material destacando também com muita ênfase a prevenção da infecção.

A estes seguiram-se muitos outros e hoje, no Brasil, já se pode contar com literatura nacional sobre todas as áreas da profissão, em livros ou periódicos. Durante muitos anos, nas áreas especializadas, as fontes de referência consultadas procediam dos Estados Unidos, em tradução para o espanhol. O impulso maior observado data de duas décadas

Dentre os periódicos publicados no Brasil ressalta-se a Revista Brasileira de Enfermagem, órgão oficial da ABEn, Enfermagem em Novas Dimensōes, agora em recesso, a Revista Gaúcha de Enfermagem, a Revista da Escola de Enfermagem da USP, Enfermagem Atual, Enfoque, O Jornal Brasileiro de Enfermagem e a novel Revista Paulista de Enfermagem. Todas elas publicam, especialmente, relatórios de pesquisas, sendo a maioria voltada para o desenvolvimento da tecnologia da enfermagem. 
CALDAS, N.P. - A Enfermagem e a Tecnologia Apropriada - Adequação da Prática à Realidade Brasileira. Rev. Bras. Enf.; DF, 35 : 81-94, 1982.

\section{4 - Influência da Pesquisa}

A pesquisa contribui para aprimorar a tecnologia, quando, através das investigaççes, valida novos procedimentos ou através de estudos sistemáticos avalia permanentemente as atividades realizadas.

E notória a influência do órgão de classe com o objetivo cultural, a Associação Brasileira de Enfermagem, no de senvolvimento técnico-científico da profissão.

A primeira pesquisa de fôlego, realizada no Brasil sobre enfermagem, foi por inicia'tiva desta entidade. Em 1956, com a ajuda da Fundação Rockfeller, a ABEn fez funcionar o "Centro de Levantamento de Recur'sos e Necessidades de Enfermagem", com o objetivo de diagnosticar as necessidades do País. O seu exaustivo relatório recomenda medidas de sentido prático para o desenvolvimento da profissão e para a correção das distorçõęs encontradas. Já agora, muitas, senão a maioria, realizada. Todas as recomendaçōes visam à melhoria da prática da enfermagem, portanto, passo decisivo para o desenvolvimento da tecnologia.

Após a conclusão do Relatório em 1959, a ABEn procurou mantê-lo atualizado através do trabalho da Documentação e Estudos.

Para incentivar as pesquisas, criou a ABEn o Centro de Estudos e Pesquisas em Enfermagem (CEPEN) que em 1979 realizou o I Seminário Nacional, sob o patrocínio do Conselho Nacional de Desenvolvimento Científico e Tecnológico (CNPq).

A ABEn levou a cabo muitas iniciativas para desenvolver a pesquisa: em 1962, publicou no seu órgão oficial de publicidade, a Revista Brasileira de Enfermagem, trabalho orientador sobre o assunto; em 1962, tratou do Tema Oficial Enfermagem e Pesquisa, que originaram recomendações específicas; em 1975, novas recomendaçōes sobre o assunto saem do Congresso; cursos foram ministrados pelas Seções da ABEn para o preparo dos enfermeiros; novamente, em 1977, novas recomendações são feitas no Ccngresso.

A abertura de concursos para Livre Dosentes, a partir da pioneira Glete de Alcântara, em 1966, e os Cursos de PósGraduação, em nivel de Mestrado, for $c m$ fatores que contribuíram para o desenvolvimento científico da Enfermagem e da Tecnologia.

$\mathrm{Na}$ realidade, a maioria das investigações realizadas na enfermagem têm sido descritivas e restritas ao campo do comportamento humano. Conquanto a vaidade destes tipos de trabalho seja comprovada, muito há que fazer em relação a pesquisas exploratórias que realmente possam contribuir para tecnologias mais adequadas.

Vale a pena conhecer o pensamento do Governo sobre pesquisas no campo da saúde.

O documento intitulado "Prioridades em Ciências e Tecnologia", da Secretaria de Ciência e Tecnologia do Ministério da Saúde, revela a preocupação de disciplinar os investimentos e de concentrar os esforços dos pesquisadores, em consonância com o III Plano Brasileiro de Desenvolvimento de Ciênıia e Tecnologia (Decreto n. ${ }^{\circ} 85.118$, de 3 de setembro de 1980). No citado documento, são consideradas áreas prioritárias de "particular interesse para o desenvolvimento de pesquisas de natureza básica, aplicada e de desenvolvimento experimental (tecnológico e operacional):

- Serviços básicos de Saúde

- Doenças transmissíveis

- Grandes endemias

- Outras doenças transmissiveis

- Alimentação e Nutrição 
CALDAS, N.P. - A Enfermagem e a Tecnologia Apropriada - Adequação da Prática à Realidade Brasileira. Rev. Bras. Enf.; DF, 35 : 81-94, 1982.

- Fármacos, imunobiológicos e plantas medicinais

- Saúde materno-infantil

- Saúde ocupacional

- Doenças crônico-degenerativas

- Informação tecnocientífica em saúde"

A expectativa governamental é de que as pesquisas sobre "Serviços Básicos de Saúde" sirvam de apoio à implantação do Programa Nacional de Serviços Básicos de Saúde (PREVSAÚDE). Chama a atenção do academicismo das pesquisas, nem sempre voltadas para o interesse da comunidade e aplicada à melhoria da saúde e ao aprimoramento da prática. Recomenda o trabalho paralelo do pesquisador com o pessoal de campo, prestador da assistência. Indica as áreas preferenciais: Organização de serviços que visará o desenvolvimento institucional ccm ênfase no "processo de regionalização dos serviços"; no desenvolvimento de recursos humanos e no desenvolvimento de sistemas de apoio (planejamento, abastecimento, manutenção, informação, avaliação e controle). A outra ênfase é para a Tecnologia simplificada em contraposição a "sofisticação desnecessária". A terceira ênfase referese a Estudos epidemiológicos e sócioeconômicos.

Na área de Doenças Transmissiveis os estudos deverão esclarecer as "eventuais correlações entre as variáveis de natureza sócio-econômica e cultural apontadas e o comportamento epidemiológico atual desse grupo de doenças”. Aponta então as grandes endemias: Malária, Doença de Chagas, Febre-Amarela, Esquistossomose, Leishamanioses, Oncocercose. Quan'to às outras dcenças transmissiveis, indica: Sarampo, Raiva, Enteroviroses, Hepatite por vírus, Zoonoses Urbanas, Doenças sexualmente transmissiveis.

No campo da Alimentação e Nutrição, recomenda que as pesquisas se vol- tem para "a busca de soluções geradoras de problemas sociais mais relevantes. Relaciona as seguintes linhas: Estado nutricional, Avaliação de políticas e programas de nutrição, Medidas de intervenção, Tecnologia de alimentos".

No que se refere aos fármacos, imunobiológicos e plantas medicinais, as pesquisas deverão contribuir para acelerar a autonomia do País em relação à produção de insumos capazes de produzir internamente os fármacos e imunobiológicos a partir da utilização da exploração da flora medicinal brasileira. Neste sentido, o Ministério da Saúde, através da FIOCRUZ e da CEME, desenvolverá dois programas especiais: o PRÓ-FÁRMACO e o PRÓ-IMUNO, cujas prioridades para pesquisa incidem sobre as seguintes linhas: Imunobiológicos e reagentes; Fármacos e matériasprimas farmacêuticas; Plantas medicinais.

A área prioritária da Saúde Materno-Infantil voltada para a mãe e a criança considera a expressão numérica deste contingente humano e vulnerabilidade do grupo. Os estudos sugeridos envolvem organização de comunidades para torná-las auto-suficientes na assistência materno-infantil; estudos sobre a "nova condição da mulher na sociedade e $o$ risco materno-infantil; estudos sobre prevenção de riscos e controle de riscos a que estão submetidos as mães e as crianças; pesquisas que visem a novos métodos de prevenção, controle e tratamento de doenças prevalentes neste grupo, especialmente as diarréias infec.ciosas e as infecções respiratórias; pesquisas sobre contraceptivos visando à avaliação da eficácia, e estudos sobre a fertilidade e infertilidade.

A Saúde Ocupasional deve ser objeto de preocupação considerando que a aceleração do cresçimento econômico do País vem sendo realizado à custa do 
CALDAS, N.P. - A Enfermagem e a Tecnologia Apropriada - Adequação da Prática à Realidade Brasileira. Rev. Bras. Enf.; DF, 35 : 81-94, 1982.

comprometimento da saúde dos trabalhadores. Os aspectos a serem explorados devem incluir: novas metodologias de pesquisa na área; estudos sobre - conceito, classificação, prevalência, diagnóstico e prevenção das doenças profissionais e acidentes de trabalho; estudos sobre o processo saúde-doença e as condições de trabalho industrial e agrícola; estudos sobre segurança e salubridade; estudos sobre modalidades de assistência em áreas urbanas e rurais; estudos sobre mudanças ambientais na área urbana e rural relacionadas com 0 desenvolvimento industrial e agrícola.

No campo das Doenças Crônico-degenerativas constituem linhas prioritárias de pesquisa: o câncer, drogas específicas para o seu tratamento, o atendimento psiquiátrioco e sobre o uso de drogas toxicomanógenas.

A linha priori'tária de Informação Tecnocientífica em Saúde visa à difusão dos resultados alcançados por todas as pesquisas realizadas; assim, poderão ser feitos estudos para determinar as reais "necessidades de informação científica e técnica da comunidade de saúde do Brasil"; "análise da estrutura da imprensa científica, na área das ciências da saúde".

O documento prevê estratégias para a viabilização das pesquisas sugerida: voltadas para os métodos, recursos e táticas.

\section{5 - Influência da Prática}

O Currículo Mínimo dos Cursos de Enfermagem e Obstetricia instituídos pelo Conselho Federal de Educação (Resolução n. ${ }^{\circ} 4$, de 25 de fevereiro de 1972) prevê um curso de graduação com a carga horária mínima de 2.500 horas, integralizáveis em 3 anos mínimos e três habilitações opcionais: Enfermagem Médico-Cirúrgica, de Saúde Pública e Obstetrícia, com carga horária míni- ma prevista para 500 horas, havendo a possibilidade dos dcis segmentos serem integralizáveis de 4 a 6 anos.

Muitas Faculdades de Enfermagem mantêm estes cursos, formando, assim, enfermeiros para 3 áreas diversificadas. Mas o que se vê na prática? O mercado de trabalho sempre está aberto para a área médico-cirúrgica. Assim testemunham os trabalhos de Carlos Gentile de Melo, quando afirmam que há distorções na assistência médica e o próprio esforço governamental em "dar uma guinada" na assistência médico-sanitária através das ações básicas de saúde e dentro do slogan "Saúde Para Todos", quando se sabe que os resultados só serão conseguidos se grande parte dos investimentos forem feitos na área da Saúde Pública e Materno-Infantil.

Assim sendo, entre as quatro paredes do hospital, a sofisticação da 'tecnologia atinge os enfermeiros que se sentem pressionados para o trabalho com as máquinas dos centros cirúrgicos, centros de terapias intensivas, centros de recuperação, centros de hemodiálise, de cirurgias cardiacas e tantos outros, principalmente nos grandes centros metropolitanos.

Sabe-se que a enfermagem é uma a'tividade da área da saúde que é desenvolvida através do trabalho de uma equipe que, quando completa, é constituída de quatro elementos: o enfermeiro, o técnico de enfermagem, o auxiliar de enfermagem e o atendente.

A legislação do exercício da enfermagem (Lei n. ${ }^{\circ}$ 2.604) data de 17 de setembro de 1955, não incluindo o atendente. Como se vê, está defasada. O seu estudo, anteprojetos e projetos vêm sendo feitos desde a criação do Conselho Federal de Enfermagem em 1973 e padece com as gestões feitas entre o Ministério do Trabalho e aquele órgão. Não somente a exclusão do atendente, que não existe de direito, mas existe de fato, mas o técnico de enfermagem que vem 
CALDAS, N.P. - A Enfermagem e a Tecnologia Apropriada - Adequação da Prática à Realidade Brasileira. Rev. Bras. Enf.; DF, 35 : 81-94, 1982.

sendo formado a partir de 1966 até agora, 1981, não tem suas funções regulamentadas. Esta é uma das razões porque contando o Brasil com 219 cursos, só teve até agora 3.77 .9 inscritos nos Conselhos. Quando se afirma que é uma das razões é porque há outras e uma delas, prende-se ao fato de que a criação dos cursos tem respaldo na Lei n.o 5.692, de 11 de agosto de 1971, que fixa Diretrizes e Bases para o Ensino de $1 .^{\circ}$ e $2 .^{\circ}$ graus, e dá outras providências, porém o Serviço Público, maior empregador de pessoal de enfermagem, não abriu vagas nos seus quadros, havendo, assim, um grande contingen'te de pessoal preparado, marginalizado, sem emprego ou subempregado.

Sabe-se que há deficiência de pessoal de enfermagem para atender às necessidades da população. Grande parte desta população recebe assistência na área da saúde, das instituições governamentais, no entanto, a porta de entrada para novos servidores, o concurso, não é realizado com regularidade, e em datas previstas. Este fato ocasiona muitas vezes o déficit de pessoal nas instituições de saúde considerando as saídas por aposentadoria, rescisão de contrato e falecimento.

A Lei n. ${ }^{\circ} 775$, de 6 de agosto de 1949, exige que a direção dos serviços de enfermagem das instituições hospitalares seja exercida por enfermeiros. Na prática, o que se vê é que as empresas "satisfazem o dispositivo legal", apresentando ao Serviço de Fiscalização de Medicina Estadual, a documentação da enfermeira, no entanto subemprega-lhe, isto é, paga salário aviltante, não exige a sua presença diária e en'trega a direção dos serviços, de fato, a atendentes ou qualquer outra pessoa desqualificada. Tudo isto com a conivência do próprio enfermeiro, que não exercendo liderança na assistência, o seu nível deixa a desejar.
Apesar de o atendente não estar incluído na Lei do Exercício da Enfermagem, este grupo representa no momento $46,54 \%$ do pessoal inscrito no Conselho Federal de Enfermagem, em todo o Brasil. Este percentual não corresponde à totalidade dos que estão em exercício, porque o provisionamento foi suspenso pelo Ministro do Trabalho até que a nova Lei do Exercício seja revista. Sendo assim, não podem ainda os Conselhos exercer a ação fiscalizadora na sua plenitude, considerando que a maioria dos que exercem enfermagem, pela falta de vínculo eom o órgão fiscalizador, ficam livres do controle, logicamente não há como coibir os abusos quanto à preservação da qualiajade da assistência.

Em grande parte das instituições hospitalares, queixam-se os enfermeiros da falta de recursos humanos e materiais para a prestação da assistência, ocasionada pela não participação das chefias no planejamento e na administração orçamentária. Não têm as chefias poder decisório sobre a aquisição de recursos, nem tampouco no estabelecimento de prioridades, ficando impossibilitada de exigir a observância integral dos procedimentos técnicos.

Grande número das instituições de saúde é dirigida por técnicos de saúde, muitos deles eficientes na sua área, porém sem qualificação para o exercício da administração de ęmpresas, razão por que facilmente se identificam as dificuldades por que passam as instituições de saúde, tão carentes de lideranças e de executivos eficientes e eficazes, desse modo incapazes de perceberem a administração como fenômeno sistêmico, isto é, de conhecerem, planejarem em conjunto as reais necessidades da instituição com as chefias e de avaliarem a assistência prestada, limitando-se a uma administração empírica, imediatista, resolvendo assuntos rotineiros e emergen- 
CALDAS, N.P. - A Enfermagem e a Tecnologia Apropriada - Adequação da Prática à Realidade Brasileira. Rev. Bras. Enf.; DF, 35 : 81-94, 1982.

ciais que são oriundos, na maioria das vezes, da falta de planejamento e organização.

\section{6 - Influência da Indústria e do Co- mércio}

A cada dia, a Indústria e o Comércio se desenvolvem no sentido de oferecerem novas opçōes de conforto e segurança ao homem, apesar do tão propalado consumismo de massa.

Não resta dúvida de que, à medida que o tempo passa, a vida se torna mais fácil, pois os instrumentos, objetos que são criados, tornam as atividades humanas mais racionais. Assim, não poderia ser diferente nas atividades da saúde. Data de três décadas a introdução dos descartáveis que em muito modificaram a tecnologia da enfermagem.

As máquinas que vêm substituindo ou suprindo as limitaçōes das necessidades básicas de respiração, alimentação, controle cárdiorespiratório, eliminação e tantas outras, pouco a pouco estão sendo introduzidas no nosso meio.

É verdade que muitos têm se preocupado com a "criação, a produção e a comercialização de aparelhos, técnicas e hábitos cada vez mais sofisticados", tanto assim que QUADRA julga que eles estão "criando, estimulando ou deformando necessidades antes, sequer, de serem consideradas, mas que, colocadas em tela, se tornam imprescindiveis e irrecusáveis". O mesmo autor julga que também têm eles contribuído para a criação de "subespecialidades antes inimagináveis"... "a despeito das propostas ingenuamente generosas de exemação de médicos de família, formação de generalistas ou médicos integrais", pois a realidade nos mostra uma prática cada vez mais instrumentalizada. Lembra ainda que muitos destes instrumentos nem sempre são utilizados na sua plenitude ou aplicados com suficiente indicação técnica, mas para justificar "a amortização do curso extorsivo" ou a "produção de lucro" resultando muitas vezes em "...desapontamentos, desilusões, descrédito, fracasso e iatrogenia". Ao concluir seu artigo "Tempos Modernos", QUADRA * assim se pronuncia:

"Ainda que, por argumentação, aceitássemos todo o avanço tecnológico como eficaz em termos de diagnósticos e terapêuticas, também deveriamos, com igual ênfase, contemplar os elevados custos financeiros e sociais envolvidos na mecânica incorporação de tais progressos à assistência à saúde. O preço da novidade é inacessivel para a maiorla da população e mesmo para os países pobres, onde apenas exaure os modestos fundos públicos. Sem renegar a tecnologia, é preciso meditar sobre a dependência econômica e por igual, sobre a dependência cultural; talvez aí se conclua que o novo não é essencialmente o melhor e que o piscar das luzes coloridas sempre iludiu o homem ingênuo."

$\mathrm{Na}$ atualidade, o enfermeiro tem participado nas instituiçōes hospitalares, da Administração de Material, integrando comissões técnicas para a escolha de produ'tos e equipamentos, testando o seu uso e dando pareceres. Existe, assim um envolvimento do enfermeiro nesta área. Alguns trabalhos publicados na Revista Brasileira de Enfermagem, assim demonstram **.

* QUADRA, Antonio Augusto F. Tempos Modernos, Informativo Científico, COCIPEHC/FCM/UERJ 2(4):89, abr. 1981.

* COSTA e AMORIM, H. de O. Gonçalves e M. José Arleo Barbosa. Participação da Enfermeira em Comissão Técnica de Material Hospitalar. RBEn 31(4):525/536 out./ dez. 1978.

** SECAF, Victória. Papel da Enfermeira na Aquisição de Material Técnico. RBEn 28(1) : 69/79, jan./mar.,1976. 
CALDAS, N.P. - A Enfermagem e a Tecnologia Apropriada - Adequação da Prática Realidade Brasileira. Rev. Bras. Enf.; DF, 35 : 81-94, 1982.

Por outro lado, sem oportunidade para opção quanto à especialidade, as enfermeiras, nos sentros utiliza dores de mão-de-obra especializada, são submetidas a remanejamentos para os CTIs, Centros Cirúrgicos e outros tantos utilizadores de aparatos cada vez mais sofisticados, sem, sequer, ser-lhes oferecidas oportunidades nas áreas das suas habilittações.

\section{7 - Influência das Entidades de Classe}

Todas as entidades de classe cumprem a sua missão de estimular o desenvolvimento e de certa forma controlar o comportamento profissional, garantindo o nível tecnológico desejável Age como mediador entre o profissional, a clientela e julgando a tecnologia empregada. Neste sentido, destaca-se a ABEn, como órgão cultural, que anualmente promove congressos, estimula a produção cien'tífica e o desenvolvimento profissional através da divulgação de experiências $\theta$ cursos.

Historicamente, a primeira entidade de classe brasileira foi a Associação Brasileira de Enfermagem, seguida das Associaçōes Profissionais, depois transformadas em Sindicatos e, finalmente, os Conselhos Federal e Regionais de Enfermagem.

Todas elas possuem objetivos que declaradamente contribuem para o desenvolvimento técnico-científico da profissão $\Theta$ procuram, através das suas atividades, alcançá-los.

A ABEn, através das suas diversas comissōes e da realização de Congressos e outros encontros regionais, oferece oportunidade de os enfermeiros desenvolverem suas pesquisas, discutirem problemas comuns e divulgarem as suas experiências.

Os Conselhos, através da inscrição e da fiscalização profissional, procuram, assim, assegurar à população assistência livre de riscas.
O Sindicato, órgão reivindicador da classe, sendo a mais nova entidade, está procurando o espaço destinado à defesa dos interesses profissicnais.

\section{8 - Influência das Iniciativas Go- vernamentais}

Paradoxalmente, a criação da primeira escola dentro do Sistema Nightingale originou-se da necessidacie de enfermeiras para a área da Saúde Pública. Pouco a pouco, as primeiras profissionais foram desviadas para a área hospitalar e, a partir daí, houve no Brasil grande ênfase à assistência hospitalar até os nossos dias. No início, o modelo era oferecido pelas Santas Casas onde a enfermagem era exercida por irmãs de caridade que apesar de manterem um bom nivel de disciplina nos serviços e de higiene, nenhum preparo possuíam no campo da enfermagem.

O panorama da assistência sanitária só sofreu algumas modificaçōes a partir da Lei n. ${ }^{\circ} 378$, de 13 de janeiro de 1937, que reorganizou o então Ministério da Educação e Saúde Pública e instituiu a Conferência Nacional de Saúde.

A primeira conferência realizou-se no periodo de 10 a 15 de novembro de 1941 e tratou da organização sanitária estadual e municipal, a ampliação e sistematização das campanhas nacionais contra a tuberculose e a hanseníase, ao desenvolvimento dos serviços básicos de saneamento e das atividades maternoinfantis.

$\mathrm{Na}$ década de quarenta, registra-se a criação do SESP e da CNCT, que absorveu grande número de enfermeiras, por estas instituiçōes, recrutadas ainda antes de ingressarem nas escolas de enfermagem pelo sistema de bolsas de estudo. Houve, então, pelo SESP o incentivo do trabalho em Saúde Pública no Brasil. 
CALDAS, N.P. - A Enfermagem e a Tecnologia Apropriada - Adequação da Prática à Realidade Brasileira. Rev. Bras. Enf.; DF, 35 : 81-94, 1982.

A segunda conferência realizou-se no período de 21 de novembro a 2 de dezembro de 1950. Nesta conferência, os sanitaristas tiveram oportunidade de apresentar seus pontos de vista sobre "orientações mais satisfatórias e de normas susceptiveis de emprestar maior uniformidade à resolução dos problemas de saúde brasileiros".

A terceira conferência realizou-se de 9 a 14 de setembro de 1963, e o temário versava sobre: "Situação sanitária da populaçāo brasileira; Distribuiçāo e coordenação das atividades médicosanitárias nos níveis federal, estadual e municipal; Municipalização dos serviços de saúde; Fixação de um Plano Nacional de Saúde."

A quarta conferência ocorreu de 30 de agosto a 4 de setembro de 1967 e versou sobre Recursos Humanos para as Atividades de Saúde.

A quinta conferência foi realizada de 5 a 8 de agosto de 1977 e o temário constou de: Sistema Nacional de Saúde, Programa de Saúde Materno-Infantil, o Sistema de vigilância epidemiológico, o controle das grandes endemias e a extensão de saúde às populações rurais.

A sexta conferência realizou-se no periodo de 1 a 5 de agosto de 1977 e tratou do controle das grandes endemias, a interiorização dos serviços de saúđe e a política nacional de saúde.

A sétima conferência ocorreu no período de 24 a 28 de março de 1980 e tratou de um único tema: Extensão das ações de saúde através dos serviços básicos.

No momento, está vigente a Lei n. ${ }^{\circ}$ 6.229 , de julho de 1975, que dispõe sobre o Sistema Nacional de Saúde, prescrevendo a conjugação de esforços dos órgãos do Governo na esfera federal, estadual, municipal, para promover a saúde do povo brasileiro.

O III Plano Nacional de Desenvolvimento $1980 / 85$ prevê mudanças para melhorar e ampliar os serviços de saú- de com ênfase na assistência primária, razão por que Haydée Dourado chamou a atenção para o novo papel do enfermeiro.

Outro fenômeno digno de nota no cenário da assistência sanitária foram as reformas previdenciárias de 1966 e 1977, que, por força deste acontecimento, estimulou a assistência hospitalar atraindo para os seus quadros grande contingente de pessoal de enfermagem.

No momen'to, o Governo pretendendo operacionalizar o propósito de "Saúde para todos até o ano 2.000", dá os últimos retoques no PREVSAÚDE. Sobre este projeto, o Conselho Federal de Enfermagem e a ABEn já manifestaram o desapontamento da classe pelo tratamento que foi dado à mesma naquele documento, de total alienação em contraposição ao estado de alerta do enfermeiro e cujas ações nos programas de stúde vão além de $60 \%$.

Data de 1975 a criação dos Conselhos Federal e Regionais de Enfermagem depois de 40 anos de lưta. Este órgão fiscalizador em muito irá contribuir no futuro próximo para o desenvolvimento da Tecnologia, principalmente na área privada onde a enfermagem está no caos, devido à falta de liderança profissional.

\section{DIRETRIZES PARA a ADEQUA- ÇÃO A PARTIR DO JOGO DAS INFLUENCIAS}

Todos percebem não ser fácil de pronto estabelecer diretrizes gerais para a adequação da prática à realidade brasileira, dentro do verdadeiro sentido da tecnologia, qual seja o de encontrar justificativas científicas para todas as ações.

$\mathrm{Na}$ análise dos diversos fatores que influenciam ou contribuem de forma positiva ou negativa para a adequação, nota-se a complexidade do assunto. 
CALDAS, N.P. - A Enfermagem e a Tecnologia Apropriada - Adequação da Prática à Realidade Brasileira. Rev. Bras. Enf.; DF, 35 : 81-94, 1982.

No prcgrama governamental do Ministério da Saúde sobre pesquisas, há respaldo para o engajamento da enfermagem brasileira com o objetivo de encontrar respostas para o caminho a seguir quanto à adequação da tecnologia.

Os programas resultan'tes da Política Nacional de Saúde, especialmente o PREVSAÚDE, contêm no seu bojo previsão de medidas que visam à adequação das práticas e o desenvolvimento de tecnolıgias apropriadas. Neste sentido, há que engajar-se as universidades e as entidades de classe com o apoio do pessoal de campo da área assistencial, da indústria $\mathrm{e}$ do comércio.

\section{CONCLUSÕES}

Entendendo-se a Tecnologia como o acervo de conhecimentos e princípios aplicados à prática profissional, identificam-se vários fatores que influenciaram na sua formação: a escola como agente de mudança e como veículo tranmissor da cultura. No Brasil, os primeiros passos para a instituição da tecnologia adveio e desenvolveu-se de criação das escolas a partir do nível superior seguida do nível médio, acompanhadas de Iniciativas governamentais para dar-lhes respaldo legal.

A produção científica como forma de cristalizar a tecnologia surgiu nas désadas de quarenta e cinqüenta e, no momento, está em franco desenvolvimento.

A primeira pesquisa em enfermagem surgiu em 1956, mas, a partir de
1962, após a reforma do ensino com o ingresso das escolas nas universidades, a pesquisa passou a dar a sua contribuição para o desenvolvimento da tecnologia ao lado dos cursos de pós-graduação.

O documento da Secretaria de Ciência e Tecnologia do Ministério da Saúde sobre Prioridades em Ciência e Tecnologia, apresenta áreas prioritárias para a pesquisa as quais permitem o engajamento da enfermagem no encontro de respostas à adequação para a realidade brasileira. Estas respostas podem ser encontradas mediante a participação das entidades de classe, conjugando esforços com a indústria, o comércio e o pessoal do campo da prática profissional.

As entidades de classe são instituições mediadoras entre a clientela e 0 profissional, no sentido de preservarlhes os interesses e resguardar a imagem do profissional.

A indústria e o comércio estão desempenhando papel relevante no desenvolvimento da tecnologia apesar das salvaguardas que se deve colocar nc rentido de não escravizar o homem a ıécnica e às máquinas, ou de torná-lo "angustiado em busca da felicidade", como diz Albino Aresi.

As administraçōes pública e privada e o Governo em sintonia com a profissão, entenderão os problemas da profissão e poderão contribuir para a adequação da tecnologia à realidade nacional. 